Research paper

\title{
Evaluation of dioxins and dioxin-like compounds from a cement plant using carbide slag from chlor-alkali industry as the major raw material
}

\author{
Yuyang Zhao ${ }^{\mathrm{a}, \mathrm{b}}$, Jiayu Zhan ${ }^{\mathrm{c}}$, Guorui Liu ${ }^{\mathrm{a}, \mathrm{b}, *}$, Minghui Zheng ${ }^{\mathrm{a}, \mathrm{b}}$, Rong Jin ${ }^{\mathrm{a}, \mathrm{b}}$, Lili Yang ${ }^{\mathrm{a}, \mathrm{b}}$, \\ Liwei Hao ${ }^{c}$, Xiaolin $\mathrm{Wu}^{\mathrm{a}}{ }^{\mathrm{b}}$, Xian Zhang ${ }^{\mathrm{a}, \mathrm{b}}$, Pu Wang ${ }^{\mathrm{a}, \mathrm{b}}$ \\ a State Key Laboratory of Environmental Chemistry and Ecotoxicology, Research Center for Eco-Environmental Sciences, Chinese Academy of Sciences, \\ Beijing 100085, China \\ b University of Chinese Academy of Sciences, Beijing 100049, China \\ c State Key Laboratory of Solid Waste Reuse for Building Materials, Beijing Building Materials Academy of Sciences Research, Beijing 100041, China
}

\section{H I G H L I G H T S}

- POP profiles from a cement kiln using carbide slag as raw material were studied.

- PCN emissions were higher than those of PCDD/Fs and PCBs.

- Mass balance showed that TEQs of all POPs were reduced by this kiln system.

- PCN emissions from the investigated system should be emphasized.

\section{A R T I C L E I N F O}

\section{Article history:}

Received 18 November 2016

Received in revised form 8 February 2017

Accepted 12 February 2017

Available online 14 February 2017

\section{Keywords:}

Cement

Dioxin

Polychlorinated biphenyl

Polychlorinated naphthalene

Carbide slag

\begin{abstract}
A B S T R A C T
Carbide slag produced from chlor-alkali industry contains high amounts of calcium compounds and can potentially be used as raw material for cement production; however, it contains large amounts of chlorine so it is essential to evaluate the emissions of chlorinated organic pollutants, including polychlorinated dibenzo-p-dioxins and dibenzofurans ( $\mathrm{PCDD} / \mathrm{Fs}$ ), polychlorinated biphenyls ( $\mathrm{PCBs}$ ), and polychlorinated naphthalenes (PCNs). A field study of the emission profiles of these pollutants in a cement plant using such slag was performed. The average concentrations of PCDD/Fs, PCBs, and PCNs in stack gases collected

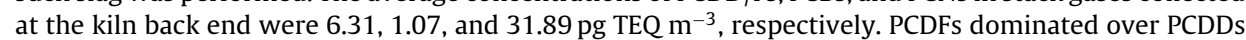
in particulate samples. Di- to pentachlorinated biphenyls were dominant homologs in the particulate samples. MonoCBs were the dominant homolog in stack gases from the kiln back end, and homolog concentrations decreased with increasing chlorine numbers. Mono- and diCNs accounted for $48-98 \%$ of PCNs. The estimated toxic equivalents of stack gas emissions of PCNs, classified as new persistent organic pollutants under Stockholm Convention, were unexpectedly higher than those of PCDD/Fs and PCBs. A mass balance indicated that all of the toxic equivalents were reduced by this cement kiln system. The highest 2,3,7,8-PCDD/F output is with clinker.
\end{abstract}

(C) 2017 Elsevier B.V. All rights reserved.

\section{Introduction}

In 2014, the amount of industrial solid waste produced in China was 3.3 billion tonnes, which was significantly more than the 2004 value of 1.2 billion tonnes [1,2]. Significant reutilization of solid wastes as resources and sustainable development of traditional

\footnotetext{
* Corresponding author at: State Key Laboratory of Environmental Chemistry and Ecotoxicology, Research Center for Eco-Environmental Sciences, Chinese Academy of Sciences, Beijing 100085, China.

E-mail address: grliu@rcees.ac.cn (G. Liu).
}

industries are important to enable environmental protection and human health. Chlor-alkali production is widely recognized as a polluting industry [3,4]: large amounts of carbide slag are produced in the generation of acetylene from the reaction of carbide $\left(\mathrm{CaC}_{2}\right)$ with water. In 2013, the annual amount of carbide slag produced in China was about 20.1 million tonnes, as a consequence of the rapid development of acetylene-involved polyvinyl chloride (PVC) production. A long-term problem for this industry is that the carbide slag occupies valuable land and can lead to pollution of soils and waters [5]. Carbide slag requires emerging disposal strategies that consider its large mass and volume: resource utilization of such solid wastes is the best approach. The calcium oxide content of 
carbide slags is about $60 \%$, and the major component of the raw materials used for clinker production is also calcium-containing minerals [6]. It has been shown to be possible to use carbide slag as the dominant component in cement production, which could save limestone resources [5]. The potential of cement kilns to use these solid wastes as raw materials is large; however, before using these wastes for cement production, it is key to understand and resolve possibly elevated formation and emissions of toxic and bioaccumulative chlorinated organic pollutants.

Polychlorinated dibenzo- $p$-dioxins and dibenzofurans (PCDD/Fs) and dioxin-like compounds, including polychlorinated biphenyls (PCBs) and polychlorinated naphthalenes (PCNs), are unintentionally produced chlorinated persistent organic pollutants (POPs). In 2015, PCNs were listed as new POPs in the Stockholm Convention [7]. POPs have adverse effects, including carcinogenicity, endocrine disruption, and bioaccumulation [8-13]. Furthermore, their persistence in the environment or biota, as well as their long-range transport on global scale [14], have led to their control and elimination proving to be an intractable problem for researchers worldwide $[15,16]$. Research into unintentionally produced POPs is important: unintentional sources of PCDD/Fs, PCB, and PCNs could include waste incineration $[17,18]$, secondary non-ferrous metallurgy [19-21], steeling-making [22-24] and other sources, such as cement kilns [25-27]. According to 2012 data, $58 \%$ of global cement was produced in China [28]. An increasing number of cement kilns are used to co-process solid wastes in China, and the release of POPs from cement kilns has been the subject of recent focus $[29,30]$. Research into POP emissions from cement kilns co-processing municipal solid wastes [31,32], sewage sludge [33,34], municipal solid waste incinerator fly ash [35], pesticides [36], contaminated soils [37], and other solid wastes is reported, but there is no available knowledge about unintentional POP emissions from cement kilns reusing high-volume solid wastes as major components of the raw materials for clinker production.

As a typical industrial process using materials involving chlorine, the chlor-alkali industry is an important source of formation and emission of unintentional POPs [38-43]. Formation and emissions of POPs in cement kilns using solid waste from this industry should therefore be investigated to determine feasibility of its intensive practical industrial application. The key concern is the levels and profiles of unintentional POP formation and release from cement plants using carbide slag that contains a high chlorine content as a raw material for clinker production. Previous co-processing studies have mainly investigated industrial wastes, including chromium slag and electroplating sludge, that might cause heavy metal pollution; solid wastes with high chlorine contents have not yet received sufficient attention [44]. To best of our knowledge, the emissions and profiles of unintentional POPs in stack gas and particulate samples in cement kilns using carbide slag as the major raw material component for clinker production have never been studied.

In this work, a field study on the emissions and profiles of PCDD/Fs, PCBs, and PCNs in a cement kiln using such slag was performed. Particulate and stack gas samples from multiple process stages of the kiln were collected and analyzed. The primary aims of this study were: (1) to evaluate the concentrations and emission factors of PCDD/Fs, PCBs, and PCNs in stack gas emissions from a cement plant using carbide slag as a major component of the raw material for clinker production; (2) to clarify the levels and profiles of PCDD/Fs, PCBs, and PCNs in particulate samples from different process stages of the cement plant. The study could provide essential knowledge to develop possible strategies and techniques to control POP releases during utilization of the slag as a resource. The results are important in promoting sustainable development of the cement and chlor-alkali industries.

\section{Experimental}

\subsection{Cement kiln description and sample collection}

The investigated cement kiln was a rotary kiln with two-stage cyclone preheaters for the raw feed (Fig. 1). A by-pass system was designed to remove chloride salts through a branched duct from the back of the kiln to ensure low chloride ion levels in the clinker and simultaneously improve conditions for reducing POP formation. The main constituent of the carbide slag was calcium hydroxide. The slag constituted $76 \%$ of the total raw material used for

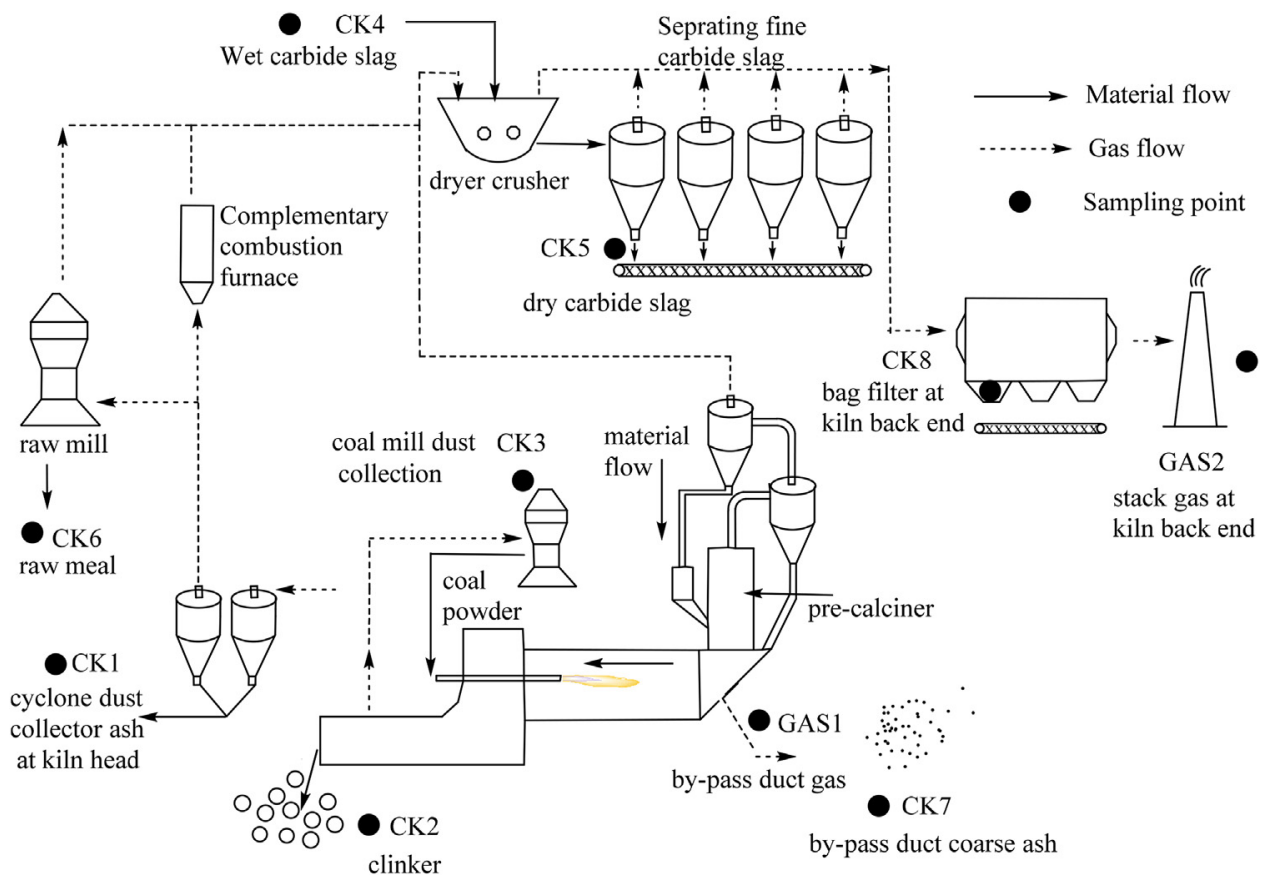

Fig. 1. Sampling points for particulates and gases in a cement kiln using carbide slag as the major raw material component. 
cement production. The kiln had a production capacity of $2562 \mathrm{t} \mathrm{d}^{-1}$ and consumed $3792 \mathrm{t} \mathrm{d}^{-1}$ raw materials, including $2880 \mathrm{t} \mathrm{d}^{-1}$ carbide slag. To evaluate the stack gas emissions of PCDD/Fs, PCBs, and PCNs, three samples each were collected at the by-pass duct (GAS1) and kiln back-end stack (GAS2), using an automatic isokinetic sampling method (equipment: Isostack Basic, TCR TECORA, Italy). The samples were collected and analyzed following the EN 1948 method, as described previously $[19,45]$. It was not feasible to collect gas samples from other process sites using this method due to the absences of a sampling platform and proper sampling port or because of high temperatures.

Heterogeneous reactions on solid particle surfaces are widely recognized as the dominant formation mechanism of unintentional POPs during industrial thermal processes [46-49]. Particulate samples from multiple different process sites were collected and analyzed, including cyclone dust collector ash at the kiln head (CK1), clinker at the outlet of the grate cooler (CK2), coal mill dust collection (CK3), wet carbide slag (CK4), dry carbide slag at dryer crusher outlet (CK5), raw feed (CK6), by-pass duct coarse ash (CK7), and bag filter fly ash at the kiln back end (CK8).

\subsection{Analytical determination of $P C D D / F s, P C B s$, and PCNs}

Congener analyses of PCDD/Fs, PCBs, and PCNs were performed as described previously [24,50]. The particulate samples were pretreated with $1 \mathrm{~mol} \mathrm{~L}^{-1} \mathrm{HCl}$, washed to near-neutral $\mathrm{pH}$, and freeze-dried. The water was then extracted with dichloromethane. The stack gas and dried solid samples after pretreatment were extracted with toluene by Soxhlet extraction for $24 \mathrm{~h}$. The dichloromethane extracts were combined with the corresponding Soxhlet extracts. A series of column cleanups, including use of multilayer silica and activated carbon columns, were used to purify the extracts. The PCDD/F, PCB, and PCN congeners were determined using isotopic dilution high-resolution gas chromatography coupled with high-resolution mass spectrometry (HRGC-HRMS) $[24,50] .{ }^{13} \mathrm{C}_{12}$-labeled PCDD/F internal standards (EPA-1613 LCS, Wellington Laboratories, Guelph, Canada), ${ }^{13} C_{12}$-labeled PCBs (EPA-1668B LCS, Wellington Laboratories), and ${ }^{13} \mathrm{C}_{10}$-labeled PCNs (ECN-5102, Cambridge Isotope Laboratories, Andover, MA, USA) were spiked before sample pretreatments. ${ }^{13} \mathrm{C}_{12}$-labeled injection standards for PCDD/Fs (EPA-1613 IS) and PCBs (EPA-1668B IS) and ${ }^{13} \mathrm{C}_{10}$-labeled injection standards for PCNs (ECN-5260) were spiked into the vials before HRGC-HRMS analysis for evaluating the recoveries of ${ }^{13} \mathrm{C}$-labeled internal standards. Concentrations of the congeners below the limits of detection were assigned concentration values equal to half of the respective limit of detection. The recoveries of ${ }^{13} \mathrm{C}_{12}$-labeled $\mathrm{PCDD} / \mathrm{F}$ and PCB standards ranged from $20 \%$ to $140 \%$, those of ${ }^{13} \mathrm{C}_{10}$-labeled $1,2,3,4,5,6,7,8-\mathrm{OCN}$ (CN75) were $10-20 \%$, and those of other ${ }^{13} \mathrm{C}_{10}$-labeled $\mathrm{PCN}$ standards were $30-80 \%$. Application of ${ }^{13} \mathrm{C}$-labeled congeners as internal standards can calibrate the loss of corresponding native targets during sample pretreatment, and is an internationally recognized optimum method for trace analysis of dioxins and dioxin-like compounds $[51,52]$. The recoveries reported in this study are acceptable for trace analysis of unintentional POPs using isotopic dilution HRGC-HRMS, as required by US Environmental Protection Agency standard methods [51].

\section{Results and discussion}

\subsection{Concentrations, toxic equivalents, and emission factors of} $P C D D / F s, P C B s$ and $P C N s$

The mass concentrations of 2,3,7,8-PCDD/Fs, dioxin-like PCBs, and dioxin-like PCNs are given in Table S1. The mass concentrations of their concentrations in GAS1, collected at the by-pass system, were $236.8,419.9$, and $18843 \mathrm{pg} \mathrm{m}^{-3}$, respectively, while those in GAS2, collected at the kiln back end, were 86.0, 384.4, and 1 $819123 \mathrm{pg} \mathrm{m}^{-3}$, respectively. The mass concentrations of dioxinlike PCNs were high in these samples, emphasizing the need for investigation of atmospheric emissions of PCNs in such plants.

World Health Organization toxicity equivalency factors (WHOTEFs) were used to calculate the toxic equivalents (TEQs) of the PCDD/Fs and PCBs [53]. PCNs have not been included in the WHO TEQ system up to now, thus TEQs of the PCNs were calculated as the sums of the concentration results multiplied by the relative potency factors for the corresponding congeners [54]. TEQ values of unintentional POPs can be used to assess the potential risk of stack gas emissions into the environment. The main pathways for unintentional POP releases into environment are via stack gas emissions because the particulates are recycled into raw materials in the kiln. The TEQ concentrations of PCDD/Fs, PCBs and PCNs

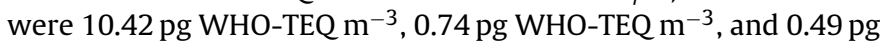
TEQ $\mathrm{m}^{-3}$, respectively, in the by-pass duct gas samples (GAS1) and

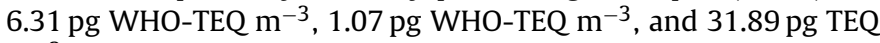
$\mathrm{m}^{-3}$, respectively, in the samples collected at the kiln back end (GAS2). These concentrations for PCDD/Fs in the stack gas samples are below the emission control limits of European Union ( $0.1 \mathrm{ng}$ ITEQ $\mathrm{m}^{-3}$ ) for cement production [55]. The concentrations of PCNs in mass and TEQ were both much higher than that of PCDD/Fs in the stack gas samples (GAS2). Since the PCNs are more volatile than $\mathrm{PCDD} / \mathrm{F}$, it is possible that they are easier desorbed and contribute to much higher emissions of PCNs in the stack gas, while PCDD/F stay more on the raw meal and are destroyed to a higher degree. The average concentrations for PCDD/Fs, PCBs and PCNs in the particulate samples were $2.31 \mathrm{pg}$ WHO-TEQ $\mathrm{m}^{-3}, 0.07 \mathrm{pg}$ WHO-TEQ $\mathrm{m}^{-3}$, and $0.13 \mathrm{pg} \mathrm{TEQ}^{-1}$, respectively. The TEQ values in the particulate and GAS1 samples were dominated by PCDD/Fs. For most industrial thermal sources, emissions of PCDD/F TEQs are normally higher than that of PCNs $[35,45,56,57]$; however, in this study, the PCN TEQs were unexpectedly higher than those of the PCDD/Fs and PCBs in the stack gas samples (GAS2) collected at the kiln back end. This phenomenon differs from that of other industrial sources, including cement kilns that co-process fly ash from municipal solid waste incinerators [35,45,56,57].

The emission factor is an important parameter for estimating total unintentional POP emissions from industries based on limited available case studies [57,58]; emission factors of PCDD/Fs, PCBs, and PCNs from cement kilns using carbide slag as the major raw material have never been evaluated. In this study, the estimated emission factors based on clinker production were $0.022 \mu \mathrm{g}$ WHOTEQ $^{-1}, 0.004 \mu \mathrm{g} \mathrm{WHO}-\mathrm{TEQ}^{-1}$, and $0.112 \mu \mathrm{g} \mathrm{TEQ}^{-1}$ for PCDD/Fs, PCBs, and PCNs, respectively. The emission factors of PCNs (in TEQ units) were obviously higher than those of PCBs and even PCDD/Fs, indicating that PCNs, as a new POP covered under the Stockholm Convention, may be an important unintentional POP that should be prioritized for focused and control in cement kilns that use carbide slag from the chlor-alkali industry as a major raw material.

\subsection{Congener profiles of $P C D D / F s, P C B s$, and $P C N s$}

The congener profiles of PCDD/Fs and PCBs can provide useful information for identifying their sources in the environment or speculation regarding their potential formation mechanisms. Fig. 2 depicts the congener profiles of 2,3,7,8-PCDD/Fs, PCBs, and PCNs in particulate and stack gas samples of this study. In the particulate samples, the proportions of 1,2,3,4,6,7,8-heptaCDF and octaCDF exceeded $47 \%$ in $2,3,7,8-\mathrm{PCDD} / \mathrm{Fs}$; in the stack gas samples, 1,2,3,4,6,7,8-heptaCDD, octaCDD, 1,2,3,4,6,7,8-heptaCDF, and octaCDF were the main congeners. In our previous study [35], tetrato hexachlorinated dibenzofurans $\left(\sum \mathrm{Cl}_{4-6} \mathrm{CDFs}\right)$ were observed 

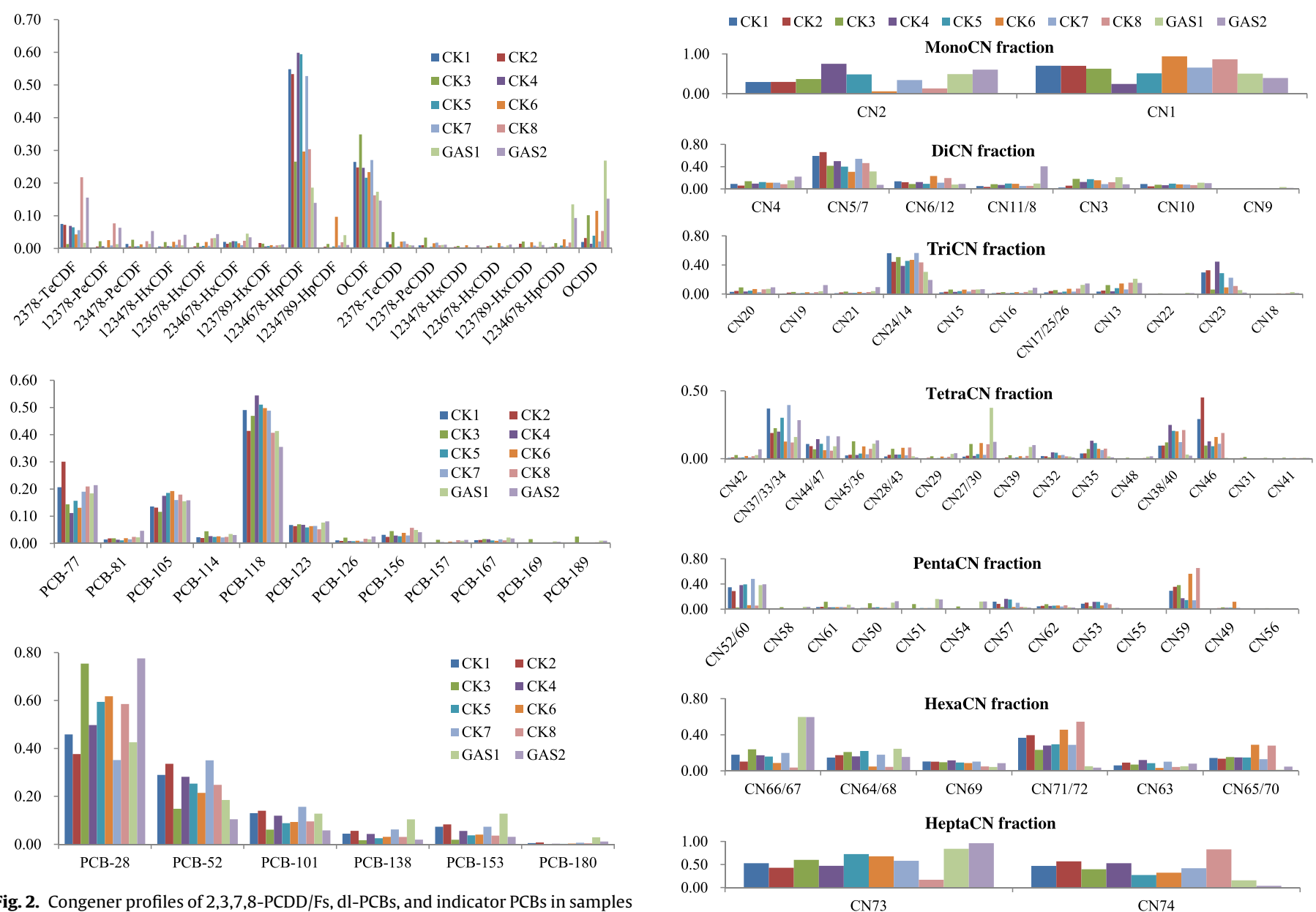

from cement kiln using carbide slag as the major raw material component.

to be the main congeners in cement kilns co-processing fly ash from municipal solid waste incinerators. The TEFs of tetra- to hexachlorinated congeners are far higher than those of hepta- and octachlorinated congeners for PCDD/Fs [53]. The sums of tetra- to hexachlorinated $\left(\sum \mathrm{Cl}_{4-6} \mathrm{CDF}\right)$ congeners in mass and TEQ concentrations are therefore a focus of this study.

The proportions of the $\sum \mathrm{Cl}_{4-6} \mathrm{CDF}$ congeners (in mass concentration of $2,3,7,8-\mathrm{PCDD} / \mathrm{Fs}$ ) ranged from $10 \%$ to $15 \%$ for particulate samples, except for bag filter fly ash (CK8) and stack gas samples (GAS2) at the kiln back end (both were 40\%). Although, the mass contributions of $\sum \mathrm{Cl}_{4-6} \mathrm{CDF}$ congeners in most samples from this plant were lower than those of the previous study, the contribution of $\sum \mathrm{Cl}_{4-6} \mathrm{CDFs}$ to the total PCDD/F TEQs was still up to $58 \%$ and $64 \%$ in the CK8 and GAS2 samples, respectively. This indicated that $\sum \mathrm{Cl}_{4-6} \mathrm{CDF}$ congeners were still the dominant contributors to PCDD/F TEQs for both the particulate and stack gas samples at the kiln back-end area in a cement plant using carbide slag as the major raw material component.

The main dioxin-like PCB congeners (in mass concentration) were $2,3^{\prime}, 4,4^{\prime}, 5$-pentaCB (PCB-118), 3,4,4'5-tetraCB (PCB-77), and $2,3,3^{\prime}, 4,4^{\prime}$-pentaCB (PCB-105). Over $80 \%$ of the PCB TEQ was contributed by $3,3^{\prime}, 4,4^{\prime}, 5$-pentaCB (PCB-126) because its TEF is higher than those of other dl-PCB congeners.

Indicator PCBs might induce important toxic effects in the environment [59]. The congener profiles of six indicator PCBs found in the samples are shown also in Fig. 2. In general, the total concentration of these six indicator PCBs accounted for $13-23 \%$ of the total PCBs in the particulate samples. PCB-28, PCB-52, and PCB-101 were the most abundant indicator congeners in both particulate and stack gas samples.

Fig. 3. Congener profiles of PCNs (shown as fractions of each homolog group) in samples of cement kiln using carbide slag as the major raw material component.

The congener profiles of PCNs in the samples are shown in Fig. 3 , and the concentration fractions of congeners in the same homolog are compared. The average ratio of $2-$ monoCN $(\mathrm{CN} 2)$ to 1 -monoCN (CN1) in the particulates was 0.77 , while the same ratio in the stack gases (GAS1 and GAS2) ranged from 0.98 to 1.53 . Similarly, the average ratio of 1,2,3,4,5,6,7-heptaCN (CN73) to 1,2,3,4,5,6,8-heptaCN (CN74) in particulates was 1.33 , while that in the stack gases ranged from 5.32 to 24.55 . It was inferred that chlorine substitutions on the 2, 3, 6, and 7 (alpha position) carbons of naphthalene were more favorable for monoCN and heptaCN in the stack gases. The dominant congeners for other homologs were as follows: $1,4 / 1,6-$ $\operatorname{diCN}(\mathrm{CN} 5 / 7)$ for diCNs; $1,4,6 / 1,2,4-\operatorname{triCN}(\mathrm{CN} 24 / 14)$ and 1,4,5-triCN (CN23) for triCNs; 1,2,5,7/1,2,4,6/1,2,4,7-tetraCN (CN37/33/34), 1,2,5,8/1,2,6,8-tetraCN (CN38/40), 1,4,5,8-tetraCN (CN46), and 1,3,6,7/1,4,6,7-tetraCN (CN44/47) for tetraCNs; $1,2,3,5,7 / 1,2,4,6,7$ pentaCN (CN52/60) and 1,2,4,5,8-pentaCN (CN59) for pentaCNs; $1,2,4,5,6,8 / 1,2,4,5,7,8$-hexaCN (CN71/72), 1,2,3,4,5,8/1,2,3,6,7,8hexaCN (CN65/70), and 1,2,3,4,6,7/1,2,3,5,6,7-hexaCN (CN66/67) for hexaCNs.

The major dioxin-like PCN congeners (shown in Fig. S1) that contributed to TEQ in the stack gas were CN2, CN1, CN73, and CN66/CN67. Mono-CNs including CN2 and CN1 are not included as POPs in the Stockholm Convention [60]. The concentrations of monoCNs were high both in particulate and gas samples (Table S4). Furthermore, CN66/67 were the congeners with higher relative potency factors (RPFs). The proportion of CN66/67 in hexaCNs was $60 \%$ in the stack gases, but $15 \%$ in the particulate samples. These four congeners contributed most of the PCN TEQ in the samples. 

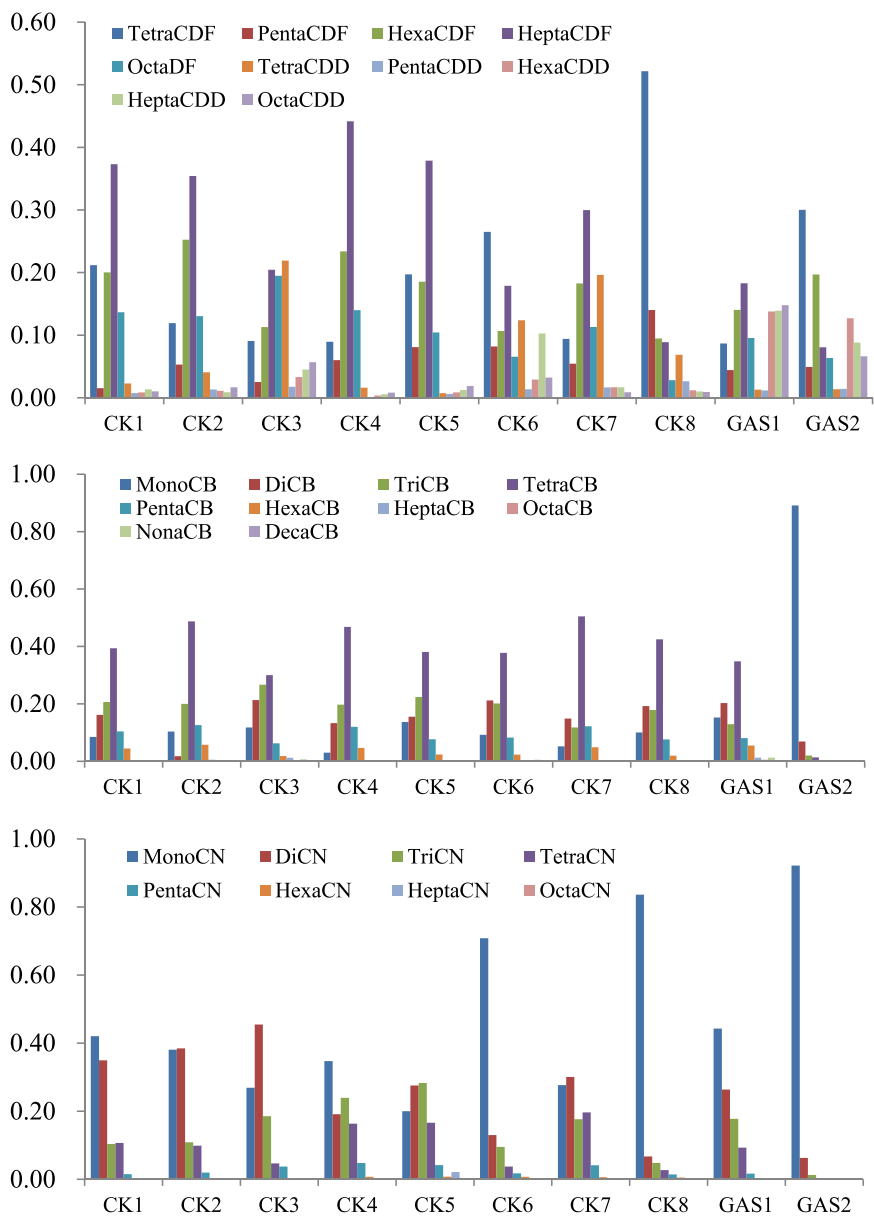

Fig. 4. Homolog profiles of PCDD/Fs, PCBs, and PCNs in samples of cement kiln using carbide slag as the major raw material component.

\subsection{Homolog profiles of PCDD/Fs, PCBs, and PCNs}

The homolog profiles of PCDD/Fs, PCBs, and PCNs can be used to demonstrate the distribution of homologs with different degrees of chlorination [61]. The homolog profiles of these species are shown in Fig. 4. The proportions of tetraCDF, hexaCDF, heptaCDF, and octaCDF were obviously higher than those of other homologs in most of the collected samples. The homolog pattern of PCDD/Fs in the bag filter fly ash collected at the kiln back end (CK8) was obviously different from that of other sites: the fraction of tetra- to hexaCDF ( $\sum \mathrm{Cl}_{4-6} \mathrm{CDF}$ ) homologs comprised $76 \%$ of total PCDD/Fs, which was much higher than those of other particulate samples (23-46\%). The proportion of $\sum \mathrm{Cl}_{4-6} \mathrm{CDF}$ homologs was $27 \%$ in the by-pass duct gas (GAS1) and 55\% in stack gas collected at the kiln back end (GAS2). The average proportion of $\sum \mathrm{Cl}_{6-8} \mathrm{CDD}$ homologs in stack gas samples was 35\%, in contrast to an average of $6 \%$ in the particulate samples. The ratios of PCDFs to PCDDs ranged from 1.7 to 27.4 in particulate samples from different process stages and from 1.2 to 2.2 for stack gas samples. The average ratios of PCDFs to PCDDs were 10.5 for the particulates and 1.7 for stack gas samples. This indicates that PCDFs are the dominant homologs that should be emphasized for $\mathrm{PCDD} / \mathrm{F}$ reduction in cement kilns using carbide slag of the chlor-alkali industry as a major raw material component. A higher ratio of PCDFs to PCDDs is widely recognized to be the indicator of a de novo pathway for PCDD/F formation in industrial thermal processes $[62,63]$. Thus, it was speculated that a de novo pathway was important mechanism of PCDD/F formation in this system. Moreover, it could be seen from Figs. 2 and 3 that the congener profiles of PCDD/Fs, PCBs and PCNs were similar for CK2 (clinker) and CK6 (raw meal). Thus, it was speculated that UPPOPs in the input material from the chlor-alkali process could be transferred into the cement kiln and partly evaporated.

Di- to pentachlorinated biphenyls contributed significantly to the total PCBs, and tetraCBs were the most abundant homologs in the particulate samples. MonoCBs were the most dominant homolog in stack gas samples collected at the kiln back end (GAS2), and the concentrations of other homologs decreased with increasing chlorine numbers. Mono- to tetrachlorinated naphthalenes contributed significantly to the total PCNs in the particulate samples. The $\sum \mathrm{Cl}_{1-2} \mathrm{CNs}$ accounted for $48 \%$ to $98 \%$ of the total PCN concentrations in all particulate and stack gas samples. From dito octachlorinated naphthalenes, the concentration of homologs decreased gradually. It is suggested that chlorination reactions might be an important pathway for PCN formation, and thermal desorption from input materials was also possible for PCNs.

\subsection{Mass balances of PCDD/Fs, PCBs, and PCNs in the cement plant}

The calculation of mass balances is helpful to better understand the inputs, outputs, and net emissions of PCDD/Fs, PCBs, and PCNs in the investigated cement plant. The daily output of clinker was $2562 \mathrm{t}$. The amounts of other materials are shown in Table S5. The average flow rates of gases in the by-pass duct and the stack at the kiln back end were 8735 and $375070 \mathrm{~m}^{3} \mathrm{~h}^{-1}$, respectively. The inputs of PCDD/Fs, PCBs, and PCNs occurred mainly through the raw feed and coal used as the main fuel. PCDD/Fs, PCBs, and PCNs in the dried carbide slag were not calculated individually because the slag was included as one of the main constituents in the raw feed. The by-pass duct gas was reintroduced into the kiln system after removal of coarse ash. The chloride content in coarse ash collected at the by-pass duct was high (Table 1) so this ash was removed from the cement kiln system to benefit the quality of clinker and reduce chlorine sources for the formation of unintentional POPs. The output of coarse ash in the by-pass system was about $4.7 \mathrm{td}^{-1}$.

Table 1

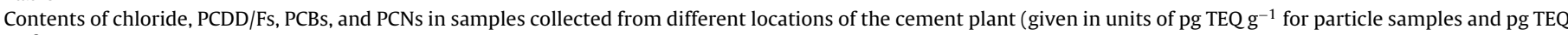
$\mathrm{m}^{-3}$ for stack gas samples).

\begin{tabular}{|c|c|c|c|c|c|}
\hline Abbreviations & Sampling sites & Chloride (wt.\%) & $\mathrm{PCDD} / \mathrm{Fs}$ (average $\pm \mathrm{SD})^{\mathrm{a}}$ & PCBs (average $\pm \mathrm{SD}$ ) & PCNs (average \pm SD) \\
\hline CK1 & cyclone dust collector ash at kiln head & 0.10 & $2.83 \pm 0.93$ & $0.07 \pm 0.003$ & $0.09 \pm 0.05$ \\
\hline CK2 & Clinker & 0.09 & $1.90 \pm 0.22$ & $0.08 \pm 0.04$ & $0.08 \pm 0.01$ \\
\hline CK3 & coal mill dust collection & 0.03 & $1.35 \pm 0.20$ & $0.07 \pm 0.02$ & $0.03 \pm 0.01$ \\
\hline CK4 & wet carbide slag & 0.34 & $2.50 \pm 0.94$ & $0.06 \pm 0.02$ & $0.07 \pm 0.008$ \\
\hline CK5 & dry carbide slag at dryer crusher outlet & 0.22 & $3.00 \pm 0.04$ & $0.06 \pm 0.01$ & $0.23 \pm 0.24$ \\
\hline CK6 & raw meal & 0.28 & $1.69 \pm 1.16$ & $0.07 \pm 0.006$ & $0.28 \pm 0.09$ \\
\hline CK7 & by-pass duct coarse ash & 1.57 & $2.66 \pm 0.82$ & $0.05 \pm 0.0007$ & $0.04 \pm 0.004$ \\
\hline CK8 & bag filter fly ash at kiln back end & 0.55 & $2.52 \pm 1.10$ & $0.12 \pm 0.02$ & $0.23 \pm 0.07$ \\
\hline GAS1 & by-pass duct gas & - & 10.42 & $0.74 \pm 0.34$ & $0.49 \pm 0.03$ \\
\hline GAS2 & stack gas at kiln back end & - & $6.31 \pm 4.71$ & $1.07 \pm 1.10$ & $31.89 \pm 7.89$ \\
\hline
\end{tabular}

a SD indicated "standard deviation", for particulate sample, duplicated analysis of PCDD/Fs, PCBs and PCNs were performed. 
Table 2

Mass balance of unintentionally produced persistent organic pollutants in a cement kiln using carbide slag as the major raw material ( $\mu \mathrm{g} \mathrm{h}^{-1}$ ).

\begin{tabular}{|c|c|c|c|c|c|c|c|}
\hline \multirow[t]{2}{*}{ congeners } & \multicolumn{2}{|l|}{ Input } & \multicolumn{3}{|l|}{ Output } & \multirow[t]{2}{*}{ Net emission } & \multirow[t]{2}{*}{ Reduction (\%) } \\
\hline & Raw meal & Coal powder & Clinker & By-pass duct coarse ash & Kiln back end stack gas & & \\
\hline$\sum 2378-P C D D F s$ & 4345 & 170 & 4513 & 9.0 & 32.3 & 39 & -1 \\
\hline$\sum \mathrm{PCDD} / \mathrm{Fs}$ & 15468 & 304 & 8586 & 22 & 74.3 & -7090 & 45 \\
\hline PCDD/F TEQ & 267 & 18 & 203 & 0.5 & 2.4 & -80 & 28 \\
\hline$\sum \mathrm{dl}-\mathrm{PCBs}$ & 9879 & 366 & 8623 & 12 & 144 & -1466 & 14 \\
\hline$\sum$ indicator PCBs & 164143 & 13671 & 102914 & 186 & 3160 & -71553 & 40 \\
\hline$\sum_{1-10}$ PCBs & 1006885 & 66230 & 498755 & 1103 & 238421 & -334835 & 31 \\
\hline PCB TEQ & 11 & 1.0 & 8.7 & 0.01 & 0.4 & -2 & 21 \\
\hline PCN mass & 1291592 & 32018 & 667362 & 534 & 720621 & 64907 & -5 \\
\hline PCN TEQ & 44 & 0.4 & 8.4 & 0.008 & 12 & -24 & 54 \\
\hline
\end{tabular}

Other particulates were normally recycled into the raw materials for cement production. The outputs of PCDD/Fs, PCBs, and PCNs were therefore mainly through clinker, by-pass duct coarse ash, and stack gas emissions at the kiln back end. Concentrations of PCDD/Fs, PCBs, and PCNs in the input and output streams are summarized in Table 1.

The mass balance is shown in Table 2. The total mass reductions of PCDD/Fs and PCBs were $45 \%$ and $31 \%$, respectively, while a net emission of $5 \%$ was observed for the PCNs. TEQ reductions of $28 \%, 21 \%$, and $54 \%$ were observed for PCDD/Fs, PCBs, and PCNs, respectively. The output of 2,3,7,8-PCDD/Fs was almost offset by their input, and the highest 2,3,7,8-PCDD/F output is with clinker. Dioxin-like PCBs were slightly reduced by about $14 \%$ and the sum of the six indicator PCBs was reduced by $40 \%$. From the congener fingerprints of the inputs and outputs, it was concluded that reductions of $\mathrm{PCDD} / \mathrm{F}, \mathrm{PCB}$, and $\mathrm{PCN}$ congeners with higher WHO-TEFs or RPFs were significant. For example, the extents of reductions of 2,3,7,8-tetraCDD and 1,2,3,7,8-pentaCDD were $41 \%$ and $38 \%$, respectively; that for PCB-126 was $20 \%$; those for CN66/67, CN64/68, CN69, CN63, CN65/70, and CN73 were $69 \%, 8 \%, 70 \%, 28 \%$, $88 \%$, and $87 \%$, respectively.

The net mass emissions for PCDD/Fs, PCBs, and PCNs were $-7086,-334566$, and $65177 \mu \mathrm{g} \mathrm{h}^{-1}$, respectively. The net emissions of PCNs were much higher than those of PCBs and PCDD/Fs. The net TEQ emissions for PCDD/Fs, PCBs, and PCNs were $-80 \mu \mathrm{g}$ WHO-TEQ $\mathrm{h}^{-1},-2 \mu \mathrm{g}$ WHO-TEQ $\mathrm{h}^{-1}$, and $-24 \mu \mathrm{g}$ TEQ $\mathrm{h}^{-1}$, respectively. The TEQ emission of PCNs was higher than that of PCBs, which was consistent with the emission factor estimations. The emission of PCNs is a typical characteristic for cement kilns using carbide slags as the major source of raw materials and differs from those of traditional cement kilns that do not co-process solid wastes [64].

\section{Conclusions}

The levels and profiles of PCDD/Fs, PCBs, and PCNs in cement kilns using carbide slag from the chlor-alkali industry as a major raw material component for clinker production are first clarified in this study. The emission factors for PCDD/Fs, PCBs, and PCNs were estimated to be $23.0 \mathrm{ng}$ WHO-TEQ $\mathrm{t}^{-1}, 3.8 \mathrm{ng}$ WHO-TEQ $\mathrm{t}^{-1}$, and $112.1 \mathrm{ng}^{\mathrm{TEQ}} \mathrm{t}^{-1}$ clinker, respectively. The average ratio of PCDFs to PCDDs was 8.04 for particulate and stack gas samples, which indicates that PCDFs are the dominant homologs that should be emphasized for PCDD/F reduction. MonoCBs were the most dominant homolog in stack gas samples collected at the kiln back end. The $\sum \mathrm{Cl}_{1-2} \mathrm{CNs}$ accounted for $48 \%$ and $98 \%$ of total PCN concentrations in the particulate and stack gas samples, respectively. Emissions of PCNs (in both mass and TEQ concentrations) were unexpectedly much higher than those of PCDD/Fs and PCBs, which indicates the importance of PCNs when considering the reduction of multiple unintentional POPs from cement kilns using this waste as a raw material. The calculated mass balance indicated that PCDD/F, PCB, and PCN TEQs are reduced in this cement kiln system.

\section{Acknowledgments}

We gratefully acknowledge support from the National 973 program (No. 2015CB453100), the National Natural Science Foundation of China (No. 21477147), Strategic Priority Research Program of the Chinese Academy of Sciences (No. XDB14020102), and the Youth Innovation Promotion Association of the Chinese Academy of Science (No. 2016038).

\section{Appendix A. Supplementary data}

Supplementary data associated with this article can be found, in the online version, at http://dx.doi.org/10.1016/j.jhazmat.2017.02. 018.

\section{References}

[1] National Bureau of Statistics of China, China Statistical Yearbook, China Statistical Press, Beijing, 2005.

[2] National Bureau of Statistics of China, China Statistical Yearbook, China Statistical Press, Beijing, 2015.

[3] Y.F. Lee, J.M. Duh, M.F. Lin, C.C. Duh, Y.C. Ling, The dioxin inventory of wastewater discharges in Taiwan, Organohalogen Compd. 71 (2009) 002649-002652.

[4] G.-Z. Jin, S.-J. Lee, H. Park, J.-E. Lee, S.-K. Shin, Y.-S. Chang, Characteristics and emission factors of PCDD/Fs in various industrial wastes in South Korea, Chemosphere 75 (2009) 1226-1231.

[5] Y. Wang, S. Dong, L. Liu, S. Cui, Using calcium carbide slag as one of calcium-containing raw materials to produce cement clinker, Mater. Sci. Forum 743-744 (2013) 171-174.

[6] Y. Wang, S. Cui, H. Wang, S. Dong, Y. Yao, Effects of preparation of cement raw meal with carbide slag on the environment and equipments, Mater. Sci. Forum 787 (2014) 123-127.

[7] UNEP, Stockholm Convention on Persistent Organic Pollutants, 2015 http:// www.pops.int/.

[8] J. Josephson, Chlorinated dioxins and furans in the environment, Environ. Sci. Technol. 17 (1983) 124-128.

[9] C. Rappe, S. Swanson, B. Glas, K.P. Kringstad, F. De Sousa, L. Johansson, Z. Abe, On the formation of PCDDs and PCDFs in the bleaching of pulp, Pulp Paper-Canada 90 (1989) 42-47.

[10] A. Schecter, J. Startin, C. Wright, M. Kelly, O. Päpke, A. Lis, M. Ball, J.R. Olson, Congener-specific levels of dioxins and dibenzofurans in US food and estimated daily dioxin toxic equivalent intake, Environ. Health Perspect. 102 (1994) 962-966.

[11] A.L. Blankenship, K. Kannan, S.A. Villalobos, D.L. Villeneuve, J. Falandysz, T. Imagawa, E. Jakobsson, J.P. Giesy, Relative potencies of individual polychlorinated naphthalenes and halowax mixtures to induce Ah receptor-mediated responses, Environ. Sci. Technol. 34 (2000) 3153-3158.

[12] D.L. Villeneuve, K. Kannan, J.S. Khim, J. Falandysz, V.A. Nikiforov, A.L. Blankenship, J.P. Giesy, Relative potencies of individual polychlorinated naphthalenes to induce dioxin-like responses in fish and mammalian in vitro bioassays, Arch. Environ. Contam. Toxicol. 39 (2000) 273-281.

[13] N. van Larebeke, L. Hens, P. Schepens, A. Covaci, J. Baeyens, K. Everaert, J.L Bernheim, R. Vlietinck, G. De Poorter, The Belgian PCB and dioxin incident of January-June 1999: exposure data and potential impact on health, Environ. Health Perspect. 109 (2001) 265-273. 
[14] S.L. Jia, Q. Wang, L. Li, X.K. Fang, Y.H. Shi, W.G. Xu, J.X. Hu, Comparative study on PCDD/F pollution in soil from the Antarctic, Arctic and Tibetan Plateau, Sci. Total Environ. 497 (2014) 353-359.

[15] W. Deng, J. Yan, X. Li, F. Wang, Y. Chi, S. Lu, Emission characteristics of dioxins, furans and polycyclic aromatic hydrocarbons during fluidized-bed combustion of sewage sludge, J. Environ. Sci.-China 21 (2009) 1747-1752.

[16] L. Guo, B. Zhang, K. Xiao, Q. Zhang, M. Zheng, Levels and distributions of polychlorinated biphenyls in sewage sludge of urban wastewater treatment plants, J. Environ. Sci.-China 21 (2009) 468-473.

[17] T. Takasuga, T. Inoue, E. Ohi, K. Senthil Kumar, Formation of polychlorinated naphthalenes, dibenzo-p-dioxins, dibenzofurans, biphenyls, and organochlorine pesticides in thermal processes and their occurrence in ambient air, Arch. Environ. Contam. Toxicol. 46 (2004) 419-431.

[18] T. Imagawa, C.W. Lee, Correlation of polychlorinated naphthalenes with polychlorinated dibenzofurans formed from waste incineration, Chemosphere 44 (2001) 1511-1520.

[19] T. Ba, M. Zheng, B. Zhang, W. Liu, K. Xiao, L. Zhang, Estimation and characterization of PCDD/Fs and dioxin-like PCBs from secondary copper and aluminum metallurgies in China, Chemosphere 75 (2009) 1173-1178.

[20] Z.Q. Nie, G.R. Liu, W.B. Liu, B. Zhang, M.H. Zheng, Characterization and quantification of unintentional POP emissions from primary and secondary copper metallurgical processes in China, Atmos. Environ. 57 (2012) 109-115.

[21] B.-W. Yu, G.-Z. Jin, Y.-H. Moon, M.-K. Kim, J.-D. Kyoung, Y.-S. Chang, Emission of PCDD/Fs and dioxin-like PCBs from metallurgy industries in S. Korea, Chemosphere 62 (2006) 494-501.

[22] A. Buekens, L. Stieglitz, K. Hell, H. Huang, P. Segers, Dioxins from thermal and metallurgical processes: recent studies for the iron and steel industry, Chemosphere 42 (2001) 729-735.

[23] D.R. Anderson, R. Fisher, Sources of dioxins in the United Kingdom: the steel industry and other sources, Chemosphere 46 (2002) 371-381.

[24] S. Li, M. Zheng, W. Liu, G. Liu, K. Xiao, C. Li, Estimation and characterization of unintentionally produced persistent organic pollutant emission from converter steelmaking processes, Environ. Sci. Pollut. Res. 21 (2014) $7361-7368$.

[25] J. Zhu, Y. Hirai, S. Sakai, M. Zheng, Potential source and emission analysis of polychlorinated dibenzo-p-dioxins and polychlorinated dibenzofurans in China, Chemosphere 73 (2008) S72-77.

[26] G. Liu, M. Zheng, M. Cai, Z. Nie, B. Zhang, W. Liu, B. Du, S. Dong, J. Hu, K. Xiao, Atmospheric emission of polychlorinated biphenyls from multiple industrial thermal processes, Chemosphere 90 (2013) 2453-2460.

[27] G. Liu, Z. Cai, M. Zheng, Sources of unintentionally produced polychlorinated naphthalenes, Chemosphere 94 (2014) 1-12.

[28] D. Song, J. Yang, B. Chen, T. Hayat, A. Alsaedi, Life-cycle environmental impact analysis of a typical cement production chain, Appl. Energy 164 (2016) 916-923.

[29] T. Chen, Y. Guo, X. Li, S. Lu, J. Yan, Emissions behavior and distribution of polychlorinated dibenzo-p-dioxins and furans (PCDD/Fs) from cement kilns in China, Environ. Sci. Pollut. Res. 21 (2014) 4245-4253.

[30] Y. Li, T. Chen, J. Zhang, W. Meng, M. Yan, H. Wang, X. Li, Mass balance of dioxins over a cement kiln in China, Waste Manage. (Oxford) 36 (2015) $130-135$

[31] E. Abad, K. Martínez, J. Caixach, J. Rivera, Polychlorinated dibenzo-p-dioxin/polychlorinated dibenzofuran releases into the atmosphere from the use of secondary fuels in cement kilns during clinker formation, Environ. Sci. Technol. 38 (2004) 4734-4738.

[32] J.A. Conesa, L. Rey, S. Egea, M.D. Rey, Pollutant formation and emissions from cement kiln stack using a solid recovered fuel from municipal solid waste, Environ. Sci. Technol. 45 (2011) 5878-5884.

[33] N.H. Rodriguez, S. Martinez-Ramirez, M.T. Blanco-Varela, S. Donatello, M. Guillem, J. Puig, C. Fos, E. Larrotcha, J. Flores, The effect of using thermally dried sewage sludge as an alternative fuel on Portland cement clinker production, J. Cleaner Prod. 52 (2013) 94-102.

[34] J. Rovira, M. Mari, M. Nadal, M. Schuhmacher, J.L. Domingo, Use of sewage sludge as secondary fuel in a cement plant: human health risks, Environ. Int. 37 (2011) 105-111.

[35] G.R. Liu, J.Y. Zhan, M.H. Zheng, L. Li, C.L. Li, X.X. Jiang, M. Wang, Y.Y. Zhao, R. Jin, Field pilot study on emissions, formations and distributions of PCDD/Fs from cement kiln co-processing fly ash from municipal solid waste incinerations, J. Hazard. Mater. 299 (2015) 471-478.

[36] D. Yan, Z. Peng, K.H. Karstensen, Q. Ding, K. Wang, Z. Wang, Destruction of DDT wastes in two preheater/precalciner cement kilns in China, Sci. Total Environ. 476-477 (2014) 250-257.

[37] Y. Yang, Q. Huang, Z. Tang, Q. Wang, X. Zhu, W. Liu, Deca-brominated diphenyl ether destruction and PBDD/F and PCDD/F emissions from coprocessing deca-BDE mixture-contaminated soils in cement Kilns, Environ. Sci. Technol. 46 (2012) 13409-13416.

[38] M.A. Fernandez, C. Alonso, M.J. Gonzalez, L.M. Hernandez, Occurrence of organochlorine insecticides, PCBs and PCB congeners in waters and sediments of the Ebro River (Spain), Chemosphere 38 (1999) 33-43.

[39] C. Bosch, A. Olivares, M. Faria, J.M. Navas, I. del Olmo, J.O. Grimalt, B. Pina, C. Barata, Identification of water soluble and particle bound compounds causing sublethal toxic effects. A field study on sediments affected by a chlor-alkali industry, Aquat. Toxicol. 94 (2009) 16-27.
[40] K. Kannan, T. Imagawa, A.L. Blankenship, J.P. Giesy, Isomer-specific analysis and toxic evaluation of polychlorinated naphthalenes in soil, sediment, and biota collected near the site of a former chlor-alkali plant, Environ. Sci. Technol. 32 (1998) 2507-2514.

[41] Z. Nie, Y. Fang, S. Tian, Y. Yang, Q. Die, Y. Tian, F. Liu, Q. Wang, Q. Huang, Perspective on polychlorinated dibenzo-p-dioxin and dibenzofuran emissions during chemical production in China: an overlooked source of contemporary relevance, Environ. Sci. Pollut. Res. 22 (2015) 14455-14461.

[42] Y. Xu, Q.H. Zhang, W.Z. Wu, W. Li, Patterns and levels of PCDD/F in a Chinese graphite electrode sludge, Chin. Sci. Bull. 45 (2000) 1471-1476.

[43] J. Jun, P. Hao, X. Tang, An inventory of potential PCDD and PCDF emission sources in the mainland of China, Organohalogen Compd. 66 (2004) 839-845.

[44] Q. Huang, Y. Yang, Q. Wang, Potential for serious environmental threats from uncontrolled co-processing of wastes in cement kilns, Environ. Sci. Technol. 46 (2012) 13031-13032.

[45] G.R. Liu, M.H. Zheng, P. Lv, W.B. Liu, C.Z. Wang, B. Zhang, K. Xiao, Estimation and characterization of polychlorinated naphthalene emission from coking Industries, Environ. Sci. Technol. 44 (2010) 8156-8161.

[46] G.R. Liu, X.X. Jiang, M. Wang, S.J. Dong, M.H. Zheng, Comparison of PCDD/F levels and profiles in fly ash samples from multiple industrial thermal sources, Chemosphere 133 (2015) 68-74.

[47] K. Tuppurainen, A. Asikainen, P. Ruokojärvi, J. Ruuskanen, Perspectives on the formation of polychlorinated dibenzo-p-dioxins and dibenzofurans during municipal solid waste (MSW) incineration and other combustion processes, Acc. Chem. Res. 36 (2003) 652-658.

[48] K. Tuppurainen, I. Halonen, P. Ruokojarvi, J. Tarhanen, J. Ruuskanen, Formation of PCDDs and PCDFs in municipal waste incineration and its inhibition mechanisms: a review, Chemosphere 36 (1998) 1493-1511.

[49] R. Weber, F. Iino, T. Imagawa, M. Takeuchi, T. Sakurai, M. Sadakata, Formation of PCDF, PCDD, PCB, and PCN in de novo synthesis from PAH: Mechanistic aspects and correlation to fluidized bed incinerators, Chemosphere 44 (2001) $1429-1438$.

[50] M. Wang, G. Liu, X. Jiang, K. Xiao, M. Zheng, Formation and potential mechanisms of polychlorinated dibenzo-p-dioxins and dibenzofurans on fly ash from a secondary copper smelting process, Environ. Sci. Pollut. Res. 22 (2015) 8747-8755.

[51] B. Wyrzykowska, D. Tabor, B.K. Gullett, Same-sample determination of ultratrace levels of polybromodiphenylethers,

polybromodibenzo- $p$-dioxins/furans, and polychlorodibenzo-p-dioxins/furans from combustion flue gas, Anal. Chem. 81 (2009) 4334-4342.

[52] G. Liu, M. Zheng, G. Jiang, Z. Cai, Y. Wu, Dioxin analysis in China, TrAC, Trends Anal. Chem. 46 (2013) 178-188.

[53] M. Van den Berg, L.S. Birnbaum, M. Denison, M. De Vito, W. Farland, M. Feeley, H. Fiedler, H. Hakansson, A. Hanberg, L. Haws, M. Rose, S. Safe, D. Schrenk, C. Tohyama, A. Tritscher, J. Tuomisto, M. Tysklind, N. Walker, R.E. Peterson, The 2005 World Health Organization reevaluation of human and mammalian toxic equivalency factors for dioxins and dioxin-like compounds, Toxicol. Sci. 93 (2006) 223-241.

[54] Y. Noma, T. Yamamoto, S.-I. Sakai, Congener-specific composition of polychlorinated naphthalenes, coplanar pcbs, dibenzo-p-dioxins, and dibenzofurans in the halowax series, Environ. Sci. Technol. 38 (2004) 1675-1680.

[55] EWID, Council Directive 2000/76/EC of 4 December 2000 on the waste incineration, Official Journal 28/12/2000, L 332/91-111, in, 2000.

[56] G. Liu, J. Zhan, Y. Zhao, L. Li, X. Jiang, J. Fu, C. Li, M. Zheng, Distributions, profiles and formation mechanisms of polychlorinated naphthalenes in cement kilns co-processing municipal waste incinerator fly ash, Chemosphere 155 (2016) 348-357.

[57] G.R. Liu, M.H. Zheng, W.B. Liu, C.Z. Wang, B. Zhang, L.R. Gao, G.J. Su, K. Xiao, P. Lv, Atmospheric emission of PCDD/Fs, PCBs, hexachlorobenzene, and pentachlorobenzene from the coking industry, Environ. Sci. Technol. 43 (2009) 9196-9201.

[58] H. Fiedler, National PCDD/PCDF release inventories under the Stockholm convention on persistent organic pollutants, Chemosphere 67 (2007) S96-S108.

[59] M. Babut, C. Miege, B. Villeneuve, A. Abarnou, J. Duchemin, P. Marchand, J.F. Narbonne, Correlations between dioxin-like and indicators PCBs: potential consequences for environmental studies involving fish or sediment, Environ. Pollut. 157 (2009) 3451-3456.

[60] UNEP, Decision SC-7/14: Listing of Polychlorinated Naphthalenes, 2015.

[61] Y. Pan, L. Yang, J. Zhou, J. Liu, G. Qian, N. Ohtsuka, M. Motegi, K. Oh, S. Hosono, Characteristics of dioxins content in fly ash from municipal solid waste incinerators in China, Chemosphere 92 (2013) 765-771.

[62] H. Huang, A. Buekens, On the mechanisms of dioxin formation in combustion processes, Chemosphere 31 (1995) 4099-4117.

[63] A. Buekens, E. Cornelis, H. Huang, T. Dewettinck, Fingerprints of dioxin from thermal industrial processes, Chemosphere 40 (2000) 1021-1024.

[64] G. Liu, J. Zhan, M. Zheng, L. Li, C. Li, X. Jiang, M. Wang, Y. Zhao, R. Jin, Field pilot study on emissions, formations and distributions of PCDD/Fs from cement kiln co-processing fly ash from municipal solid waste incinerations, J. Hazard. Mater. 299 (2015) 471-478. 